\title{
MONITORING OF TRACK SECTIONS WITH LONG-PITCH CORRUGATION
}

\author{
Jan Valehrach*, Jaroslav ŠmíD \\ Brno University of Technology, Faculty of Civil Engineering, Institute of Railway Structures and Constructions, \\ Veveři 331/95, 60200 Brno, Czech Republic \\ * corresponding author: valehrach@fce.vutbr.cz
}

Abstract. The focus of this paper lies on monitoring of the track sections with rail corrugations caused by wheel sliding. Short waves on the running surface of the rail head on low rail are typical for this defect. Long-pitch corrugation is a significant cause of vibration and noise pollution in the railway infrastructure. Therefore it is very important to understand the formation and development of this imperfection of the rails. Measurements were carried out in curves of small radii on several tracks in the Czech Republic. In addition to the measurement of the surface of the rail head a number of supplementary parameters was evaluated for each section, such as curve radius, superelevation, track gauge etc. and the speed of passing trains as well. This paper describes rail corrugation defect and its development. Our early results are presented in the Conclusions.

KEYWORDS: long-pitch corrugation, rail, track, measurement, speed .

\section{INTRODUCTION}

During the past recent time the railway infrastructure administrators are pushed to change their approach to the maintenance of the sections affected by the long pitch corrugation. These defects were not as frequent as they are in these days and also some of them have not been considered as a serious problem for the operability of the track. There are more factors to blame, such as increases of the track speeds, higher track loads or also (predominantly in the close vicinity of the cities) higher frequency of the passenger trains. In addition, today's customers are not only satisfied with just the travel from point $\mathrm{A}$ to $\mathrm{B}$ or with the shortest time of transfer. They also require more comfortable travelling. It is not very difficult to notice the imperfections of the track or the increased noise levels. And there is also the second aspect of the problem, which some say is even more important - that is the influence of the imperfections for the adjacent neighborhood, such as vibrations, noise and quakes, all significantly reducing the quality of life of the people living near tracks.

There is no doubt about the negative effects of the long-pitch corrugation. Everyone is able to recognize that the train is much louder when passing through the curve degraded by corrugations in comparison with the passage of the same curve after the replacement of the rails. The tracks with the long-pitch corrugation require more frequent and also more costly maintenance (such as rail grinding, replacement of the rails etc.). In order to fulfil interoperable function within Europe the railway network has "to ensure a safe and uninterrupted operation of trains achieving set levels of performance" [1. Accordingly, it is necessary to guarantee required quality of the railway infrastructure and to reduce maintenance cost to min- imum. With the above mentioned reasons in mind we should endavour to understand the formation and development of this defect.

\section{THEORY OF Formation OF LONG-PITCH CORRUGATION}

The long-pitch corrugation, sometimes called also as "short waves", is a sinuous inequality of the running surface of the rail. Distance between wave peaks is usually between 8 and $30 \mathrm{~cm}$ and the depth ranges between 0.1 and $1.2 \mathrm{~mm}$. A typical location, where long-pitch corrugation could be found, is the lower rail in curves of radius less than $600 \mathrm{~m}$, sometimes even $700 \mathrm{~m} \mathrm{[2,} \mathrm{3.} \mathrm{The} \mathrm{cause} \mathrm{of} \mathrm{these} \mathrm{corrugations} \mathrm{is}$ the difference in length that each wheel of the wheelset rolls along the curve on the low and high rail. This difference also causes the wheel slip, occurring mostly on the low rail. Slip happens not only in the longitudinal direction, but also in the lateral direction. In most cases, long-pitch corrugation does not occur alone. Such defects, which are accompanying the long-pitch corrugation, can be sorted to:

- those supporting the development of long-pitch corrugation (such as side wear of the outer rail),

- those emerging as a consequence of long-pitch corrugation (cracked clips).

Since the processes surrounding the long-pitch corrugation are not documented in their entirety it is often complicated to distinguish which defect is the cause and which is the consequence. Therefore, the consecuting list of defects does not take into account the above mentioned division: damaged baseplates, sleepers with transverse cracks, missing parts of fastening, cracked sleeper screws, cracked clamps in rail 


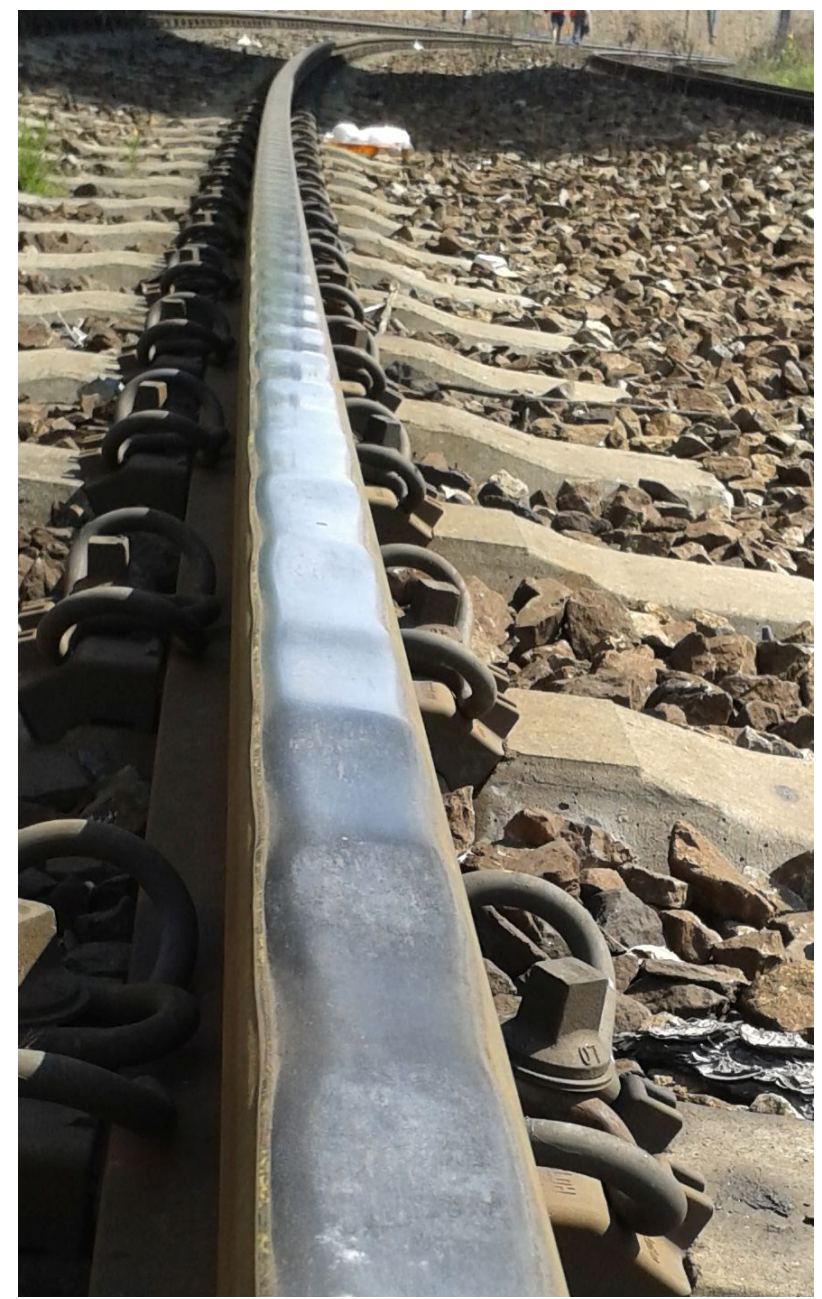

Figure 1. Long-pitch corrugation in Havlíčkův Brod

fastening, abraded ballast behind sleeper heads etc.

\section{Selection of Lochtions And MEASUREMENT}

Appropriate sections for the monitoring of long-pitch corrugation, where typical signs of this defect occur, were chosen in association with the Railway Infrastructure Administration of the Czech Republic (SŽDC). Further criteria which have influenced the selection of sections originated from the identical or at least similar characteristics and features of curves, such as:

- curve radius,

- track cant,

- traffic load and others.

Subsequently, an assessment of the available data for all the individual sections was conducted. The frequency of measuring was determined with consideration to previous maintenance work, rail traffic present and planned intentions of the SŽDC as well. The majority of sections are double tracks thus it is possible to compare two monitored locations on one track or one location on each track, for example in a measured curve. To be able to understand more thoroughly the development of the long-pitch corrugation it is also necessary to observe other factors, which influence the defect. One of these factors is the matter of variety composition of the trains (meaning the split up between passenger trains and freight trains). Variety composition of the trains complicates the whole matter, since it adds more other unknown influences. That is the reason, why we try to rule this factor out if possible. It is less difficult to succeed when considering the case with one track; hence it is more likely that the track would be passed in both directions equally. This also allows us to compare two sections within one location between themselves. On the other hand, in the case of the double track there is no certainty that both tracks would be passed with the same amount of trains or even with the same rate between the passenger and freight traffic. As an example, in some cases we can distinguish the acceleration of trains in one track and deceleration or even stopping of trains in the second track (like when approaching an entry signal of railway station). That is why it is not possible to perform comparison between the sections in different tracks within one measuring location. In both cases the monitored sections are chosen by the presume of the influence on formation and development of long-pitch corrugation, by the track alignment, by the permanent way design itself (composition of the superstructure including the effects of tested design elements such as more elastic fastening to the sleepers, clips with increased fatigue limits, under sleeper pads) and by the substructure design (e.g. the influence of the bedrock, bridge structure etc.). The sections are monitored in regular intervals depending on the present state of development of defects, traffic volume, maintenance and repair works etc. The sections with recently replaced rails allow us to observe the formation and development of long-pitch corrugation in its initial stages. Measurements were repeated after 3 months. In sections, where the defects are more developed, the time between the measurements was almost doubled, since the corrugations are more noticeable (deeper and significantly better visible). That allows us to measure each wave separately. On the other hand, the measurements in sections, where defects are not yet fully developed should be performed with increased frequency, so it is easier to cover the whole development process.

As you can see on Figure 2, the long-pitch corrugation forms very interesting shapes which are changing fluently throughout the curve.

Apart from the visual inspection (which confirmed the suitability of our selected locations) all of the sections are monitored and documented using the following methods:

- visual inspection and photo documentation,

- measurement of track geometry by the trolley Krab,

- measurement of wavy deformations of the rail head by the device Salamander, 


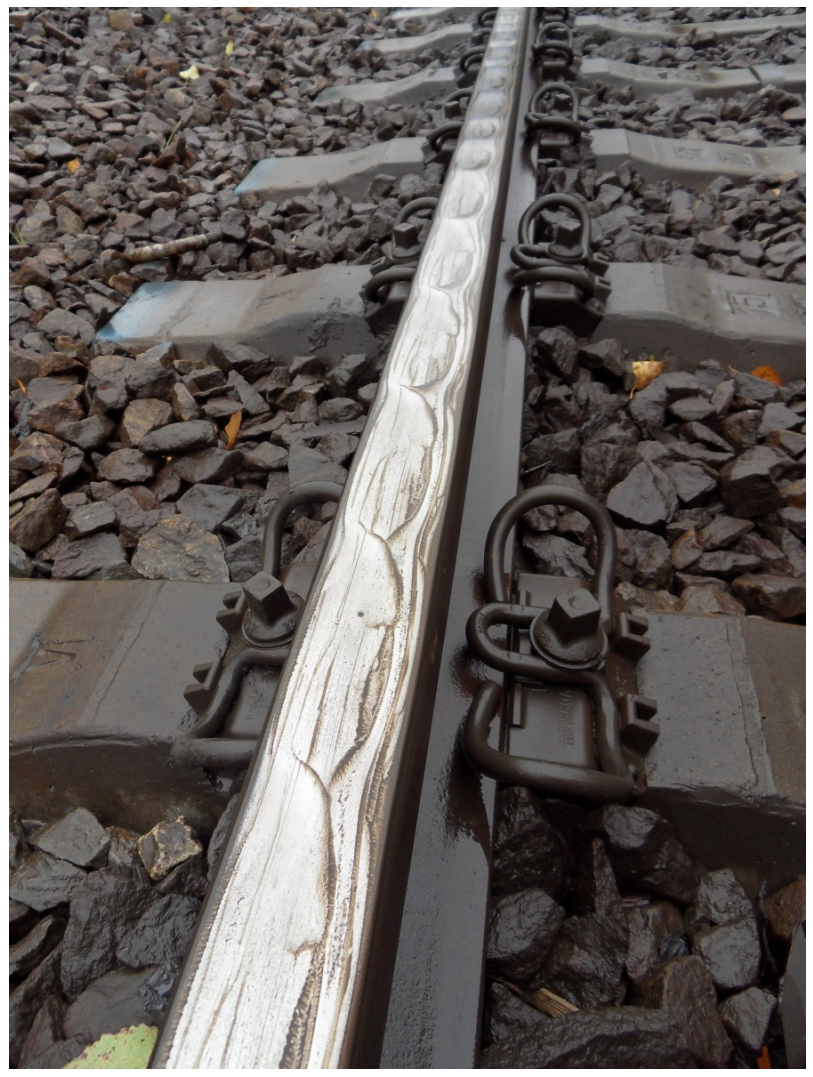

FIGURE 2. Highlighted long-pitch corrugation by contaminant in Havlíčkův Brod

- monitoring of the speed of trains and train compositions.

The track geometry is measured to describe the current state of the track, which unfortunately in many cases does not correspond to the data found in the railway documentation. Another reason for these measurements is the need for additional information such as track gauge, gauge widening etc. The microgeometry of the rail head, specifically wavy deformations, was measured using the device Salamander. Unfortunately, in some cases it was not technically possible to measure a curve as a whole, which is the reason, why only few selected sections were measured within these locations. Measured data are evaluated by the device in accordance with EN 13231-3 44 in wave lengths:

- $10 \div 30 \mathrm{~mm}$,

- $30 \div 100 \mathrm{~mm}$,

- $100 \div 300 \mathrm{~mm}$,

- $300 \div 1000 \mathrm{~mm}$.

This categorization is not fully appropriate for our purposes since long-pitch corrugation can appear with a wave length shorter than $100 \mathrm{~mm}$ [3], particularly in small radius curves. Based on the theory of formation of long-pitch corrugation [6], our own measurements and data comparison, it can be said that the two categories for $30 \div 100 \mathrm{~mm}$ and $100 \div 300 \mathrm{~mm}$ wave lengths can be merged together for the purposes of

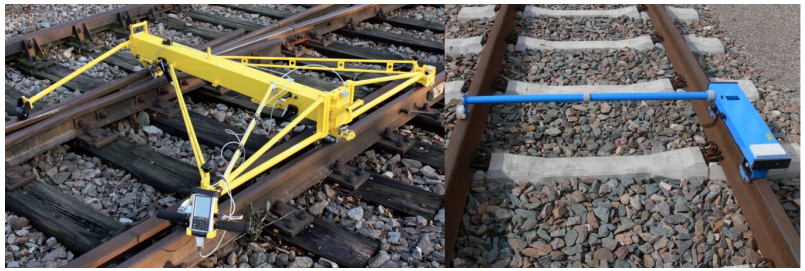

Figure 3. Trolley Krab (track geometry) [5] and Salamander (corrugations)

monitoring long-pitch corrugation. In both zones, the same or very similar wave amplitudes are achieved.

Apart from the monitoring of the long-pitch corrugation of the rail head, other critical elements were evaluated as important and thus were observed:

- compliance with technology of construction and maintenance works,

- compliance with technology of works in stations,

- composition of passing trains,

- operation of rail vehicles with respect to the track speed.

During the measurements, the influence of the difference between the track allowed speed and actual speed of the vehicles proved to be imperative. That is the reason for closer observation of the traffic with respect to the measured speed of trains. In some cases the track allowed speed, or sometimes cogitated as a designed speed, differs significantly from the actual speed of the vehicles. This phenomenon occurs more often these days, since there is an effort of the track designers to maximize the speed limits as much as possible (they tend to "squeeze out" the most of the infrastructure) and mostly could be found on tracks with very heterogeneous traffic flow, consisting of the various ratios of the passenger and freight trains. The more freight trains pass throughout the section of the track, the bigger is usually the difference.

Generally, the difference between the allowed and actual speed produces a cant excess or cant deficiency. Analogically, these values grow parallelly to the difference, so when the difference increases, the values increase accordingly. Therefore, a weighted average of all speed measurements in a set section was calculated, when the mass of each train was taken into consideration. The masses of the trains for the purposes of the weighted averages have been obtained by two ways. The weight of passenger trains was taken from the passenger carriages charts and from the database of the train compositions. The mass of the freight trains could be found out from the mass normatives (which is the maximum allowable mass of the whole train). The problem is that the actual load on the train is not known and thus it is not possible to know the right mass of the train. Therefore the masses of the freight trains were estimated with only one value around 1000 tonnes. This approach brings the significant amount 
Measurement: MDK 51120144037 , Line: Vyskov, Start Km: 1, Rail: 1

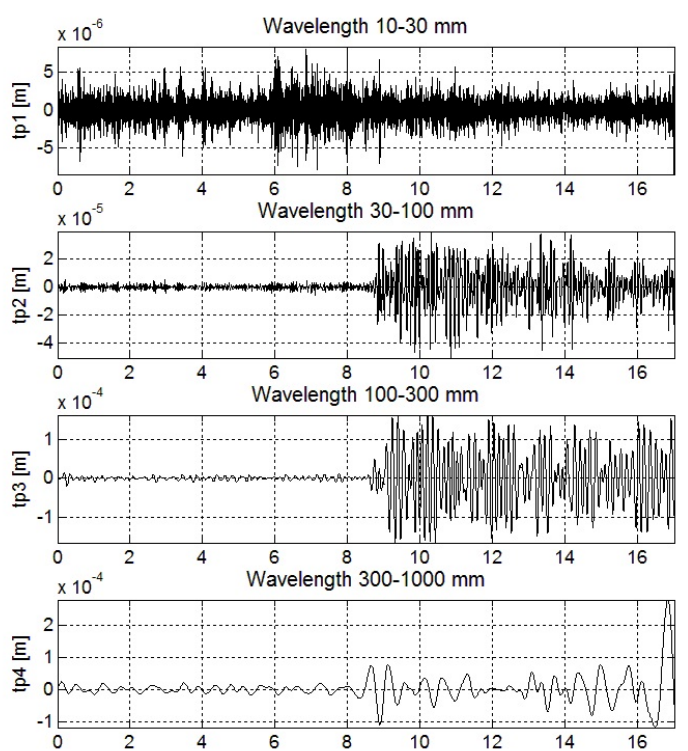

Figure 4. The processed record from the device Salamander shows a track, where in one part the rails were replaced and in the other part the rails with long-pitch corrugation were left.

of uncertainty to the result, but on the other hand, according to higher order masses of the freight trains in comparison to the passenger trains, the sensitivity of the result to the changes of the masses is quite small. Then for the calculation of the cant excess and the cant deficiency the following scheme was used.

Assuming a formula for speed of trains

$$
V=\sqrt{\frac{D * R}{11,8}}
$$

The cant excess then applies

$$
E=D-\frac{11,8 * V^{2}}{R}
$$

and analogically for the cant deficiency

$$
I=\frac{11,8 * V^{2}}{R}-D
$$

Ideally, the effects of cant excess and deficiency should be balanced, especially with respect to train masses. However, in some sections cant excess markedly dominates. That happens for example in the vicinity of stations, where the trains are accelerating and have not yet reached the track speed or where the greatest amount of the track load consists of slow moving trains (usually freight trains). In such locations this leads to the overload of the railway superstructure and consequently results in increased occurrence probability of the defects.

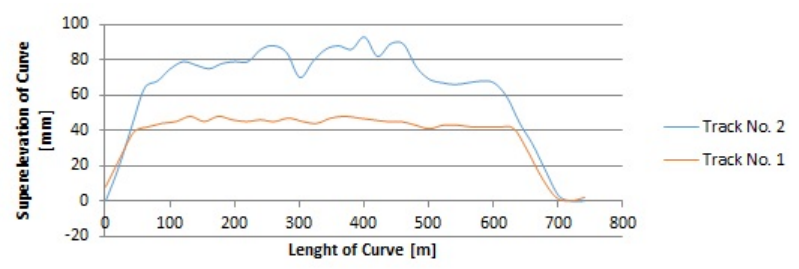

Figure 5. Cant in track No. 1 and in track No. 2 in curve A.

\section{Outputs}

\subsection{Measuring Location HavlíčKůV BROD}

One of the monitored track locations is a part of the track No. 324 Havlíčkův Brod - Kutná Hora in between the $\mathrm{km} 224.394$ and $\mathrm{km} 225.150$ in approach to the station Havlickuv Brod from the direction Kutna Hora. The location consists of a double track with consecuting reverse compound curves. First curve is for the purposes of this work named A and is closer to the station. The second curve is named B and is located further from the station in direction Kutná Hora. The cant of the track was measured, using the device Krab, which showed a different value of the cant for each track. The results of the train speed measurements were the differing speeds of trains in both tracks and both curves. After the calculation of the weighted averages, the data revealed the presence of cant excess in both tracks and both curves.

The train speed in the curve A in the track No. 1 is affected by braking/accelerating near Havlíčkův Brod station. Some freight trains heading from Kutná Hora stopped at the station head in such a way that the end of the train was standing in the curve $(\mathrm{E}=2 \mathrm{~mm})$. Unfortunately, this situation is a common practice in Havlickuv Brod. It facilitates the document handover by the stopping of the locomotive just in front of the station building. The data proved that both rails are nearly under the same load, since the weighted average E/I was close to zero. The record of the wavy deformations for wave lengths $100 \div 300 \mathrm{~mm}$ is shown on Figure 6 on the first line. For the curve A on track No. 2 the weighted average equals $\mathrm{E}=$ $27 \mathrm{~mm}$. When comparing with the track No. 1 the wavy deformations reach the amplitudes twice as high (Figure 6, second line).

On the contrary the cant excess markedly dominates in the curve $\mathrm{B}$ in comparison to the curve $\mathrm{A}$. The weighted average the curve $\mathrm{B}$ equals $\mathrm{E}=57 \mathrm{~mm}$. The state of microgeometry as shown on Figure 6 (fourth line) is practically identical to the curve A of this track. The track No. 1 of the curve B is passed with almost all trains with an cant excess $(\mathrm{E}=72$ $\mathrm{mm}$ ) since they have to reduce the speed according to a change of allowed speed between the curves. In the past, the railway infrastructure administrator tried to improve the situation by reducing the allowable 

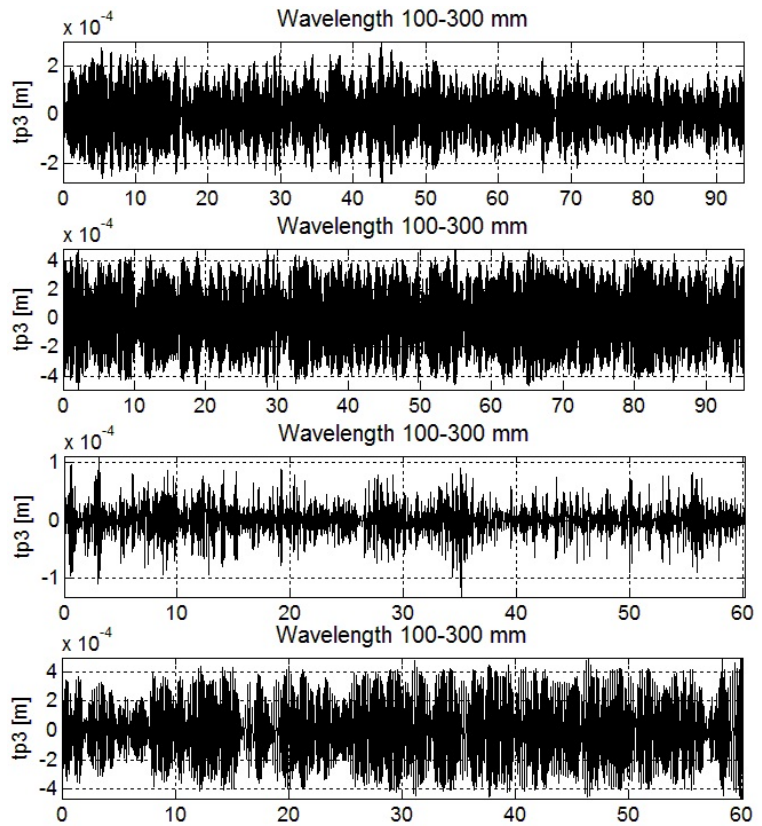

Figure 6. Category of wavelengths 100 Ãů $300 \mathrm{~mm}$ Havlickuv Brod (from the top: curve A of the first track, curve A of the second track, curve B of the first track and curve $\mathrm{B}$ of the second track).

speed to $55 \mathrm{kph}$, nevertheless this action had an adverse effect. Instead of going at $70 \mathrm{kph}$, the trains are decelerating to $55 \mathrm{kph}$ already during the passage through the curve B. Additionally; the freight trains which are approaching the station and intended to pass through the first turnout in the side direction have to be slowed down just before the pass of the entry signal at $40 \mathrm{kph}$, which is located in the middle of the curve B. This forces such trains to travel with the reduced speed for more than 500 metres before the station. The designed cant in the curve B of 142 $\mathrm{mm}$ is from that reason unnecessarily large and corresponds to the recommended cant DN1 for speed $75 \mathrm{kph}$ (recommended cant is the value of the cant prescribed by the standard CSN 73 6360-1 [7]). The allowable speed in this curve is on the other hand only $70 \mathrm{kph}$ and moreover the speed, which is achievable realistically is even less - just $55 \mathrm{kph}$. Surprisingly, the wavy deformation of microgeometry is less developed in this section in comparison to other measured sections (as it could be seen on the Figure 6(third line)). One of the possible explanations of this phenomenon may be the usage of the under sleeper pads, which were installed in this curve and only in the track No. 1. According to [8], it is possible to install under sleeper pads to affect the behaviour of sleepers in a desired zone of the frequency spectrum. This is the way how it is possible to suppress the generation of vibrations and noise emissions in these frequencies. Part of the energy of dynamic processes is emitted from vibrating sleepers as noise. For newly built track with under sleeper pads an increased level of noise was measured (in just units dB). Such a track shows over time slower development of imperfections of the rail heads. As a consequence, the noise levels for these tracks are lower than for comparable tracks without under sleeper pads. For this reason, not only the noise pollution, but also other parameters, such as vibration parameters, sleeper and rail movements and development of irregularities of the rail head are monitored on the test sections in the Czech Republic. The railway superstructure in the location Havlickuv Brod consists of the rails $49 \mathrm{E} 1$, fastenings E40 with clamps E14 in the curve A and Skl40 in the curve B, then sleepers B 91S/1 on both tracks. The difference between used fastening systems could not be considered as a cause of the change in the defects, since the replacement of the fastening system was the result of the development of the defects and should have been the resolution of the problem. The long-pitch corrugation was found on both tracks. Additionally, massive cracking of clamps Skl14 occurs in the curve B. It is surmised that high value of the weighted average of cant excess contributes to defects of the clamps. Despite of the fact that the above mentioned data indicated that higher values of cant excess have the most adverse effect on microgeometry, the slowest development of the long-pitch corrugation occurred in the curve B in track No. 1.

\subsection{MeAsuring LOCATION HADY}

The monitored location Hady is the opposite to the location Havlíčkurv Brod in the means of the unequal cant excess. In this location the cant deficiency plays the main role. This section could be found on the track from Brno to Česká Třebová between km 161.685 and $\mathrm{km}$ 164.485. During the year 2015 the rails of the track No. 1 have been replaced and the development of the long-pitch corrugation thus could be observed and measured since the time zero i. e. from the perfect condition. The measuring location consists of two sections, first is located in front of the tunnel A (curve A), the second is located in front of the tunnel B (curve B). Both monitored sections lay only in the track No. 1, but the line is double track. The usual direction of the passing trains in the track No. 1 is from the tunnel B to the tunnel A, which is the heading from Česká Třebová to Brno.

Figure 7 shows the comparison of development speeds of wavy deformations (here represented as a percentage of the boundary overrun of the RMS limit value, RMS = Root Mean Square) in both curves in location Hady. Initial analyses of the data show significant differences in development of the long-pitch corrugation in the curves with small radii. Considering the common structure and geometrical parameters of the track (curve radii $283 \mathrm{~m}$ and $261 \mathrm{~m}$, cant 123 $\mathrm{mm}$ in both curves, fastening W14, sleepers B $91 \mathrm{~S}$ etc.) and the railway superstructure they do not exhibit significant differences. The curve B (in front of the tunnel B) embodies the weighted cant deficiency $\mathrm{I}=67 \mathrm{~mm}$. The curve A (in front of the 

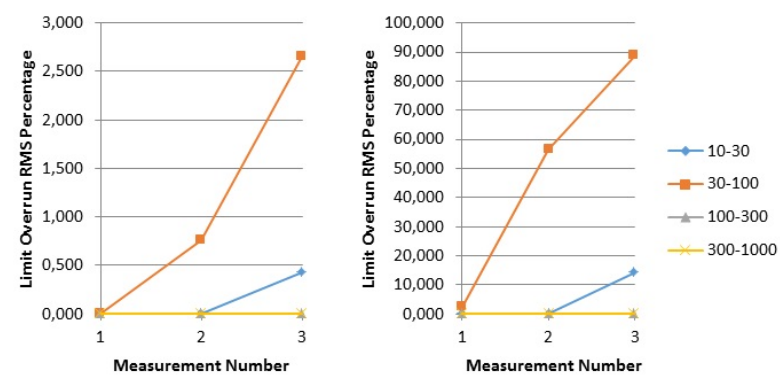

FiguRE 7. comparison of RMS values [\%] (to the left the measuring point in front of the tunnel $\mathrm{A}$ and to the right the measuring point in front of the tunnel $\mathrm{B}$ in location Hady.

tunnel A) shows the weighted cant deficiency $\mathrm{I}=47$ $\mathrm{mm}$. Unfortunately, these values have to be considered as tentative, since the train speeds were affected by the day time in which the measuring took place. The majority of the recorded trains were passenger trains; the freight trains pass this location mostly at nights due to very strong suburban traffic. Also it has to be pointed out, that the track configuration is similar to that in the location Havlíčkův Brod (namely the curve A of the track No. 1). There is a turnout located just behind the measuring location and freight trains approach the station through the side direction of the turnout at $60 \mathrm{kph}$ at maximum. Passenger trains pass the turnout in straight direction at speeds up to $70 \mathrm{kph}$ ( or up to $75 \mathrm{kph}$ for trains using the cant deficiency $130 \mathrm{~mm}$ ). When we take into consideration that the measured train speeds were just tentative, the calculation offers results, in which the values for cant deficiency are logically lower (for the section in front of the first tunnel). This partial conclusion shall be confirmed or refused as soon as possible.

\section{Conclusions}

Various parameters were monitored on the two measuring locations. In the every curve there could be found a different combination of factors affecting the development speed of the long-pitch corrugation and in some curves a different track parameter can be the dominant factor. Nevertheless, it can be declared at the present time and based on our measurements and observations, that the speed of passing trains undoubtedly plays the significant role on the development of defects. The adverse effect of the speed occurs in two forms:
- the higher the value of the speed, the more significant the development of the defect,

- the higher the value of the cant inequity occurs, the more significant is the defect.

At the current state of the research it might be said that the higher the speed or the bigger the difference between the actual speed of the vehicle and the designed track speed, the faster and greater the development of the defects. The curve radius has to be considered as a fixed parameter at all times, since its change in order to reduce the development of the long-pitch corrugation is in most cases nearly impossible, we have to focus on another parameters. The composition of the railway superstructure and setting of the appropriate speeds of trains and also appropriate cant values seem to be promising factors. Whether these parameters alone would be sufficient the following research will show.

\section{ACKNOWLEDGEMENTS}

The presented results were obtained with the support of Centre for Effective and Sustainable Transport Infrastructure (TE01020168), Student's grant tender of the Faculty of the Civil Engineering of the Brno University of Technology (FAST-J-15-2860) and Railway Infrastructure Administration, state organization (SZDC s. o.).

\section{REFERENCES}

[1] R. Čech. Interoperabilita a rozvoj ždc [online], 2015. [2016-02-11], https://www.fd.cvut.cz/personal/ tyfal/str/predmety/ikod-pr/ikod10.pdf

[2] C. Esveld. Modern railway track. 2nd ed. Zaltbommel: MRT-Productions, 2001. DOI:ISBN 90-800-3243-3

[3] H. Funke. Broušení kolejnic, 1992.

[4] En 13231-3. railway applications - track - acceptance part 3: Acceptance of reprofilling rails in track, 2012.

[5] s. s. r. KŽV. Krab system [online]. [2015-12-26], http://kzv.cz/English/krab.php

[6] J. Valehrach. Skluzové vlny - teorie a praxe, 2015. DOI:ISBN 978-80-214-5091-2

[7] ČSN 73 6360-1. Konstrukční a geometrické uspořádání koleje železničních drah a její prostorová poloha - Část 1: Projektování, 2008.

[8] Plášek O., Hruzíková M. Př́nos podpražcových podložek ke zvyšování kvality geometrických parametrü koleje, In Zborník prednášok z konferencie s mezinárodnou úcastou Pozemné komunikácie a dráhy, Environmentálna kapacita pozemných komunikacií a dráh. Košice, Technická univerzita v Košiciach, 2006. ISBN 80-8073-602-2. 